\title{
Revisiting Medicalization: A Critique of the Assumptions of What Counts As Medical Knowledge
}

\author{
Tiago Correia* \\ School of Sociology and Public Policies, ISCTE - Instituto Universitário de Lisboa, Lisbon, Portugal
}

The concept of medicalization is hugely influential, and empirical studies have demonstrated that medicalization has largely been achieved not only through the work of medical professionals or scientists but also increasingly through the efforts of patients or citizens seeking to legitimize their distress through defining it as a "medical" problem. In this article, I argue that the concept of medicalization is still fundamentally important to the sub-discipline of medical sociology, but that there is a need to revisit and critique its conceptualization. I draw on reflexive arguments within the literature that we, as sociologists, have tended to reproduce the assumptions of the medical profession about what counts as medical knowledge and practice and on literature that explores the

OPEN ACCESS

Edited by: Nicola Kay Gale, University of Birmingham, United Kingdom

Reviewed by:

Assaf Givati,

University of Portsmouth, United Kingdom Rachel Thwaites,

University of Lincoln, United Kingdom

*Correspondence:

Tiago Correia tiago.correia@iscte-iul.pt

Specialty section:

This article was submitted to Medical Sociology,

a section of the journal

Frontiers in Sociology

Received: 15 February 2017 Accepted: 04 September 2017 Published: 19 September 2017

Citation:

Correia T (2017) Revisiting Medicalization: A Critique of the Assumptions of What Counts As Medical Knowledge.

Front. Sociol. 2:14. doi: 10.3389/fsoc.2017.00014 complex and plural ways in which people seek to make sense of their illnesses. I argue that there have been few attempts to engage with the question of how "making things medical" occurs in a global context of medical pluralism. By revisiting Conrad's approach to defining medicalization, I argue for a separation between empirical observations of the dominance of biomedical knowledge, from theoretical observations about medical knowledge and definitions. I argue for a "knowledge-based" approach to medicalization by opening up the definition of "making things medical" to include all forms of medical knowledge in a global society. The concept of medicalization can then be replaced with medicalizations (plural). To argue this, I take two steps: first, I draw on hermeneutic philosophy to argue that there is a stable definition of medicine on which to base an argument that apparently diverse forms of medical practice can be grouped together and used within the concept of medicalization; second, I argue that medicalization is not unproblematically linked to medical social control. The "success" or not of different attempts to define things as medical problems in part depends on the social and political context. This new approach allows sociologists to make sense theoretically of differences we see in comparative empirical research between whether "diseases" are acknowledged in different national or cultural context. Finally, I provide the readers with guidance on the operationalization of this concept in empirical study.

Keywords: medicalization, demedicalization, medical social control, ontology of medicine, professionalization

\section{INTRODUCTION}

The concept of medicalization in sociology originated within a particular societal-politicalhistorical context characterized by the dominance of professionalized (bio)medicine. The concept describes the processes and effects of medicine's link to social regulation and control. Over time, the concept often became used to articulate a normative position of defense or criticism of medical power 
in relation to lay users, other health professionals, and regulators (Rose, 1994). Furthermore, attempts to adapt the concept to the complexity of contemporary societies has resulted in growing attention to "co-evolving processes" (Williams et al., 2017, p. 778) rather than to medicalization itself, as illustrated through concepts, such as biomedicalization (Clarke et al., 2010), and CAMization (Almeida, 2012). The first addresses the way technoscientific knowledge is changing the definition of life and the role of medicine in the enhancement of biological selves. The second describes the process through which complementary and alternative medicines act in western societies as countervailing forces in the attempt to gain socio-political and scientific legitimacy before the state, clients, and clinicians (see also Kelner et al., 2006).

Despite this proliferation of related concepts, recent debate has argued for the continued relevance of the concept of medicalization to the sociology of health and illness (Busfield, 2017, Williams et al., 2017). The discussion on the medicalization-demedicalization boundary (e.g., Conrad and Schneider, 1980; Riessman, 1983; Burke, 2011; Halfmann, 2012) is a useful example of its relevance, but it also illustrates the extent to which a proper discussion of what counts as medical and non-medical is lacking in the debate despite the overall understanding that medical knowledge is adaptive [think of preventive, predictive, personal, and participatory medicine (Hofmann, 2016)].

It is with these ideas in mind that I introduce in this article a knowledge-based critique of medicalization. This approach makes a link to the perspectives in hermeneutical philosophy on the conceptualization of medicine. I seek to demonstrate the ongoing value of the concept of medicalization in sociological analysis and demonstrate that its use can be analytically neutral (less normative) in relation to different players and the nature of medical knowledge. To make this argument, I revisit the work of Peter Conrad. The focus on Conrad does not ignore that the term "medicalization" has been differently used among sociologists since the late 60s [see Busfield (2017) for an overview of these differences]. However, given Conrad's key position in the debate, both inside and outside sociology and the attention we need to give to the issue of what should count as medical knowledge and definitions, his work provides a useful start point for discussion. The issue of medical knowledge and definitions has remained poorly explored in the literature that followed over recent decades, and therefore, I would argue, that misleading and biased interpretations of medical knowledge have been reproduced as the debate has grown and become more complex.

The remainder of the paper is organized as follows. First, I critique the way that medical knowledge has been understood in the concept of medicalization and argue for the importance of developing a different conceptual framework, which I term "knowledge-based." This new framework allows different (nonbiomedical) branches of medical knowledge, irrespective of the political or scientific status of these branches in society, to be the basis for medicalization. Second, I explain the assumptions that underlie this approach by drawing on hermeneutic philosophy to argue that there is a stable concept of medicine on which to base an argument that apparently diverse forms of medical practice can be grouped together and used within the concept of medicalization. Then, I argue that medicalization is not unproblematically linked to medical social control. Third, I describe some operational steps for empirical studies using the knowledge-based approach to medicalization and its main implications for the wider sociological debate. I end with a summary of the key arguments.

\section{THE PROBLEM}

Medicalization first entered the vocabulary of social scientists (Pitts, 1968; Szasz, 1970) to address the "tendency [of] medical institutions to deal with non-conforming behavior" (Broom and Woodward, 1996, p. 358). The concept speaks to the influence and role of medical regulation in daily life, which replaced previous social control institutions, namely the church and the law, in the management of deviance as explanations for human health conditions gradually changed from sin, to crime, and eventually to sickness.

Sociological debates about medicalization have encountered several critiques. These include the issue of whether human conditions and behaviors are facing pressure for medicalization, or whether demedicalization or remedicalization better describe contemporary trends (Conrad, 1977, 1979, 1992, 2005, 2007; Lowenberg and Davis, 1994; Williams, 2002, 2004; Conrad and Leiter, 2004; Adler and Adler, 2007; Torres, 2014); the durability of the concept in the context of societal transformations such as growing criticism and mobilization against medical authority (Rose, 2007) and critiques of the theoretical assumptions in medicalization (e.g., some branches of social constructionism perceive the reference to medicalization as a reification of medical power and legitimacy Bury, 1986).

In a recent article by Busfield (2017), she re-examines these critiques and argues that medicalization remains as empirically and conceptually relevant in late modern society as ever as a consequence of medicine's continuous influence in everyday life. Williams et al.s (Williams et al., 2017) response to Busfield's article agrees with her defense of medicalization but highlights problems in her approach to its definition, in particular the fact that the concept contains "elastic" categories that expand and contract over time, and that medicalization can occur on different levels (conceptual, institutional and interactional) (Williams et al., 2017, p. 775-776). This debate highlights the extent to which definitions of medicalization continue to need further clarification. I note Peter Conrad's claim that "the key to medicalization is definition" (Conrad, 2007, p. 5) and, therefore, I argue that it is useful to revisit the literature to reassess some of the grounding arguments on the emergence of medicalized societies and whether they continue to hold up in the context of pluralist and global societies.

Peter Conrad's work on the medicalization of society suggests that medicalization happened in a relatively well circumscribed time and scope of medical knowledge: "The medical profession and the expansion of medical jurisdiction were prime movers for medicalization" (Conrad, 2007, p. 9); “[medicalization is] the result of intentional expansion by the medical profession" (Conrad, 1992, p. 211); it involves "licensing the medical profession to provide some type of treatment for it [disease]" (Conrad, 1975, p. 12); it means that "human problems [enter] the jurisdiction 
of the medical profession" (Conrad, 1992, p. 210); that "physicians are most directly involved"; and that medical diagnosis and treatment are based on "prescribing drugs" (Conrad, 1992, p. 211). In short, the underlying assumption is that the emergence of medicalization is linked to the medical profession in the West, which is known to have developed out of a specific branch of knowledge built on biology and physiology, and closely supported by technological practices and evidence; hence its designation as biomedicine or biological medicine (Hofmann, 2001).

Given Conrad's focus on the processes that Western societies underwent from the twentieth century onward with the extension of medicine's domain, it is fair to say that his conceptualization of medicalization is empirically grounded. Nevertheless, Conrad's own concern with the definition of medicalization raises an important and challenging issue. He argues that, "The interest in medicalization has predominantly focused on previously non-medical problems that have been medicalized, but actually medicalization must include all problems that come to be defined in medical terms" (Conrad, 1992, p. 211). This calls into question how to define "medical terms." My argument is that defining medicalization as the process through which things are made medical requires a clear theoretical standpoint as to the definition of medical knowledge, and may be quite distinct from the empirical context that Conrad and others were studying.

If the distinction between empirical context and theoretical scope of medicalization are not properly acknowledged, as sociologists we risk reproducing a misleading and culturally biased argument: that medicalization refers only to Western biomedical knowledge (see for instance Furedi, 2008 on medicalization in therapy culture). The reason I consider it misleading and culturally biased is because it is grounded on a profession-based view of medicine. For medicalization of society to exist medical knowledge had to be accepted, produced, and reproduced by players beyond medical professionals per se, such as regulatory institutions (e.g., legal, political, and educational), other health professions more closely related to biomedicine (e.g., nursing), lay knowledge, and other actors in health not entirely related to the medical profession (Conrad, 2007; Williams et al., 2017). It is necessary to acknowledge that what makes medical knowledge exist without the direct intervention of its practitioners is the institutionalization of medicine's social control, and that this could only have taken place after medicine had undergone a process of professionalization. Here, I draw on neo-Weberian perspectives on the professions, which argue that professionalization is the result of closure processes in the access to education, credentials, and practice, which underpin the institutionalization of social control (Saks, 2015). Professionalization of medicine thus refers to the process in which, on the basis of laboratory-based knowledge built on biology and physiology, control over non-clinicians and other branches of knowledge previously defined as medical was institutionalized. (I return to this issue below.)

Consequently, when the theoretical and empirical scopes of medicalization are not separated, the concept automatically reproduces the meaning, content, and position of medicine in Western countries. This can help explain much of the criticism toward medicalization, either for not being accurate in addressing the growing opposition to medical authority (Ballard and Elston, 2005) or for contributing to the legitimation of medical dominance (Rose, 2007). It also affects the understanding of concepts that resonate with the empirical-based view of medicine, such as biomedicalization (Clarke et al., 2010) and CAMization (Almeida, 2012). My reference to these concepts is not critical given that technoscientific structures and knowledge and growing battles for recognition by complementary and alternative medicines practitioners in health are undeniable transformations that contemporary societies are facing. The issue, in my view, is that concepts such as these should sit within a broader umbrella concept of medicalization and not discussed as "alternatives" (Busfield, 2017) or as "co-evolving processes" (Williams et al., 2017).

There are several criticisms of accepting what I have termed an empirically grounded view of medicalization. One criticism is that the notion of medicalization loses its adaptive dimension and is, therefore, essentialist in relation to the medical/non-medical boundary. Medicalization, demedicalization, and remedicalization, therefore, mean human conditions and behaviors entering and leaving the realm of biomedical knowledge. Another criticism is that the concept becomes normative in relation to the different players and types of knowledge in health care. Not surprisingly, most empirical analyses of medicalization take place where Western biomedicine has been institutionalized as medicine. Emerging exemptions from the non-Western world similarly strengthen this link (e.g., Conrad and Bergey, 2014; Lahiri-Dutt, 2015). The expansion of laboratory medicine across the globe and of consumerism, informed societies, global-scale medical tourism, and the role of transcontinental regulatory agencies in health help to explain the growing acceptance of this overlap beyond the West (Conrad, 2007). A third criticism is that this view of medicalization is less accurate in understanding the complexity of processes, knowledge, and medical practices and operates as if medicine had started to influence everyday life only a century ago and only in Western countries. The influence of medicine in the Western world before the nineteenth century and outside the Western world (e.g., Ayurveda or traditional Chinese medicine) is clearly indicative of the fact that the theoretical scope of medicalization should not be linked exclusively to one specific branch of knowledge. Otherwise, the concept becomes yet another indication that the discussion in medical sociology has been narrowed to the specific development, institutions and knowledge structures in Western countries (Bradby, 2016).

\section{THE RELEVANCE OF A KNOWLEDGE- BASED APPROACH TO MEDICALIZATION}

It is justifiable and necessary to ask what "medical terms," "language," "framework," and "interventions" medicalization actually refers to. Is it to medicine more broadly or biomedicine more specifically? In order to provide a clearer answer to this question, I argue that there is a need to introduce a knowledge-based approach to medicalization to replace the profession-based approach that is most common in the debate. The idea is to show, as suggested by Busfield (2017) and Williams et al. (2017), that the concept can be more analytical neutral in relation to different players and different forms of medical knowledge and therefore to prove its ongoing relevance in the current debate in medical sociology. The 
expression "knowledge-based approach" means that the concept of medicalization must be broad enough to include the different branches of medical knowledge, irrespective of the political or scientific status of these branches in society.

In summary, there are three areas that I argue would enhance our understanding of the concept of medicalization. First, there is a need to acknowledge that the concept of medicalization comprises both theoretical and empirical scopes of analysis. Second, the theoretical scope of medicalization should be separated from empirical observations. This enables a critical exploration of variations in medicine in both time and space including the branches of knowledge defined as medical; the different degrees of social control linked to medical knowledge; the players allowed to exercise such control; and the procedures considered appropriate. Third, medicalization is inherently adaptive, as it is not specific to particular medical knowledge and players.

\section{TWO UNDERLYING ASSUMPTIONS}

The position I propose here is based on the separation of medicine as a theoretical reality and medicine as an empirical reality. My argument is that this difference has not always been properly recognized in the debate on medicalization. There are at least two results. One is the difficulty in understanding the theoretical scope of medicalization in Conrad's definition (making things medical) and the other is the idea that acceptance of medicalization reflects a normative defense of biomedical power.

My argument that these two scopes should be separated is defended on the basis of two assumptions. One is the ontological existence of medicine, i.e., in which we can find common traits in medical practice and knowledge in spite of the changes that medicine has undergone, especially since the eighteenth century. The other is the explanation that social control of medicine should be regarded as the result of a broader political process in societies. It is a process that explains the professionalization of medicine, which is why Conrad is right in saying that, from the most abstract point of view, medicalization precedes social control. My argument is, therefore, that, from an analytical point of view, medicalization and social control should remain separate. Any failure to separate these concepts analytically reifies the frontiers between what is considered medical or non-medical and is normative in relation to the other branches of knowledge excluded by political processes.

\section{The Ontology of Medicine}

The first underlying assumption that I make is about medicine's nature, its ontology. The argument is that whereas there are obvious differences in how medicine turns out empirically, sociology needs to acknowledge medicine's founding principles and features that remain stable over time and in the different branches of knowledge. This has been so at least since Hippocrates, who is considered in modern Western countries to be the first practitioner to have rationalized the etiology of diseases as treatable by natural means (e.g., Ferngren, 2009).

A philosophical exploration of medicine's ontology is one way to theorize medicine apart from empirical observations. Furthermore, it allows us to address Conrad's definition of medicalization as "defining a problem in medical terms, using medical language to describe a problem, adopting a medical framework to understand a problem, or using a medical intervention to 'treat' it" (Conrad, 2007, p. 5).

According to an ontological view of medicine, its presence in society-medical knowledge, players, practices and proceduresshould be looked at as the result of influences and disputes among the different branches of knowledge either in relation to each other or in relation to patients and regulation instances (e.g., Porter, 1989; McVaugh, 1993; Saks, 1996). This understanding includes the time when medicine consisted of deregulated and not even necessarily related branches of knowledge and the divisions between them were blurred and adaptive among and within countries (e.g., Hippocrates' humoralism, Galen's physiological system, Dioscorides' use of herbs, Aristotle's relationship with nature, practices labeled as magical, mythical, quackery, or witchcraft). Some examples described since the Middle Ages include maternal diseases; heart, liver, and nerve diseases; and aches, colds, and fevers (see Porter, 1995 and Walker, 2013 for a detailed description). It also includes the modern scope of laboratory medicine when medical knowledge in Western countries was first subject to large-scale regulation (Lindemann, 1999; Johnson and Chaudhry, 2012).

My view of medicine's ontology builds on Gadamer's (Gadamer, 1996) hermeneutical philosophy. Medicine is defined as an "art" (from the Greek techne) in the sense that it uses discretionarybased skills that are taught to turn abstract principles into concrete situations according to specific "truths" (from the Greek logos). Regardless of whether the truth stems from humoralism, morals, physics, chemistry, biology, or physiology, the production of rationalized "work" (from the Greek ergon) encompasses all medical praxis. The main rationalization in medicine is the process of recovering health, given the overall understanding that practitioners' intervention in the course of treatment or healing is at most partial. The factors out of the practitioners' control include limited knowledge of the etiology of diseases, patients' predisposition to be helped, and their trust in the procedures used (see Fox, 1957, 2000 or Montgomery, 2006 on some sociological adaptations of these arguments).

It could be argued that biomedicine lost this Aristotelian view of "work" in the light of positivist assumptions underpinning today's scientific rationale. However, Gadamer (1996) makes clear that despite practitioners' greater capacity to change the course of natural life through technical and technological intervention built on scientific evidence and methods (though even this capacity is sometimes more rhetorical than effective), two features of modern and classical medical techne have remained unchanged. The first is the scope of praxis. Medical decisions continue as contingency-dependent as ever, even in the context of clinical protocols and guidelines. Think of the clinician's eye, feelings, and experience in supporting medical decisions. How clinicians think and apply knowledge to concrete situations remains intrinsically discretionary and thus only partially controllable (Atkinson, 1995; Timmermans, 2010, see also Kinsella and Pitman, 2012 on the Aristotelian concept of phronesis as applied to modern professions). Think also of the contextually embedded nature of scientific knowledge [e.g., see Bourdieu (2004) on the effect 
of school contexts on scientific learning or Lakatos (1968) on scientific communities].

The second feature is the aim of medical practice. Although the categories of health and disease and practitioner-patient interaction have changed profoundly over time, we should not disregard medicine's judgment and quest for ordered explanations of health and disease as intrinsic to medical practice (Toulmin, 1993; Downie and Macnaughton, 2000).

\section{The Link of Medicalization to Social Control}

The second underlying assumption has to do with reassessing the commonly accepted link of medicalization to social control. Social control is often regarded as part of medicalization (see among others Riessman, 1983 or Davis, 2006). Although this link is easy to understand in relation to biomedicine in Western countries, it could not be further from the theoretical scope of medicalization. Conrad himself stated, "On the most abstract level medical social control is the acceptance of a medical perspective as the dominant definition of a certain phenomenon" (Conrad, 1979, p. 511-512), thus "medicalization precedes medical social control" (Conrad, 1992, p. 216).

When medicalization draws on biomedical knowledge this relationship is easily inverted, i.e., social control can precede medicalization. The inversion reflects the disputes involving practitioners of different forms of medical knowledge for clients and state legitimacy at the time when medical social control began to expand in society (Wailoo, 2004; Larson, 2012). The historical literature seems to agree on two arguments in this regard. One argument is that initial forms of medical social control date back to the late seventeenth century as part of the collectivization of everyday life events in which the functioning of nation-states exposed the human body to growing normalization, normativization, and moralization (e.g., the rise of sanitary, preventive, and assistentialist medicine, see Foucault, 1979a,b; Armstrong, 1983; Lupton, 1995). The other argument is that generally in Western countries disputes among different forms of medical knowledge (e.g., naturalism, humoralism, philosophy, and so on) formally ended only in the nineteenth and twentieth century [e.g., the UK Medical Act in 1858 and the US National Board of Medical Examiners in 1915, see Freidson (1970) and Johnson and Chaudhry (2012)]. In short, both arguments highlight that forms of medical social control took place before medicalized societies had been consolidated [e.g., the medicalization of prenatal care is said to have only taken place in the US in 1935, see Barker (1998)].

Drawing on the neo-Weberian social closure theory applied to professions, disputes among branches of medical knowledge and other health care practices are part of the process of the professionalization of medicine. From this standpoint, I argued that the overlap of medicalization and biomedicine entailed a profession-based approach to medicalization. Professionalization is the process of closure in which occupations succeed in selfregulating both access to and the implementation of knowledge in accordance with specific rules and codes of conduct (Hughes, 1958; Wilensky, 1964). As originally noted by Zola (1972), this control can only be effectively achieved after practitioners: (i) secure the content of their knowledge against other, competing knowledge and (ii) ensure the extensive political and legal protection of that knowledge.

The key issue in the acceptance of medicalization as overlapping with the "bio paradigm" is that medical social control is not intrinsic to biomedical knowledge. Actually, the way in which medicine replaced the church and the law as a mechanism of social regulation is the result of the role nation-states in governing everyday life (Zola, 1972; Pinell, 2011). For this reason, Conrad is right to argue that medicalization is prior to medical social control. Things that are made medical exist in societies regardless of whether medicine exerts social control. For instance, the work by Weisz (2003) shows that medicine related differently to states, sometimes even at the same time, either in a close relationship (e.g., France) or more loosely (e.g., Britain) and that this has affected the levels of social control afforded to medicine. He also demonstrates that full adherence to biomedical epistemology and service ideals did not occur until after states had licensed medicine on a national scale.

What these arguments highlight is that biological medicine only institutionalized medical social control (the process usually referred to as the medicalization of society) after having successfully monopolized the truths of the medical field, thereby becoming a profession. Therefore, medical social control emerged before the medical profession actually existed as such.

Therefore, what happened in Europe at the turn of the nineteenth to the twentieth century was not the rise of medicalization of society as one can assume by the overlap between medicalization and biological knowledge. Rather, it was the comprehensive institutionalization of medical social control through the professionalization of medicine (Porter, 1999). Medicalized conditions and problems existed before and will continue to exist irrespective of the degree and scope of medical control in societies.

\section{SOME OPERATIONAL STEPS}

My attempt to critique and clarify Conrad's theoretical scope of medicalization (making things medical) builds on a philosophical definition of medicine that is independent from its empirical existence in context. The result is that the conceptualization of medicalization embraces several medicalizations, i.e., any branch of medical knowledge can medicalize life. Without acknowledging the plurality of medical knowledges, the sociological position is empirically biased and normative about the different branches of medical knowledge and reproduces the boundaries set by forms of medical knowledge that succeed in institutionalizing social control. My argument is not that, from an empirical point of view, medicalization and social control do not overlap, because it was precisely this that happened in the industrialized countries with the biomedical paradigm. The central point is that medicine has a theoretical (in additional to an empirical) existence and, therefore, the definition of what is and what is not medical cannot be bound by purely empirical processes.

The key operational steps required to use this knowledgebased approach to medicalization are as follows. The first step 
is to accept that the medicalization of human conditions and behaviors could result from activities within all branches of medical knowledge, regardless of their status and place in society. I have already discussed that the establishment of medical definitions is deeply embedded in tensions and disputes among the different branches of knowledge and in their relations with states. Therefore, accepting an inclusive definition of medicalization is a key step. It also acknowledges the fact that when one branch of knowledge exerts social control over society as a whole, as is the case of biomedicine in the West, it does not prevent other branches from medicalizing behaviors and conditions as well, even if they do it partially or entirely outside the influence of nation-states.

My proposal to open medicalization to different medical knowledges carries the risk of an inaccurate definition of medicine, thus making it necessary to adopt a clear analytical standpoint that establishes clear boundaries of what is medical and what is not. Accordingly, the second step is the need to test the adherence of the different branches of knowledge to medicine's ontological features (the scope of praxis and the aim of practice), according to which medicine can be defined as the use of discretionary-based skills that are taught to turn abstract principles into concrete situations according to specific truths aimed at health recovery (see the detailed explanation in the Section "The Ontology of Medicine").

The third step is to make it clear in relation by what specific etiology human conditions and behaviors are labeled as medical. Acknowledging the form of medical knowledge used is essential to identify the type of medicalization that is being addressed (e.g., biology and physiology, humoralism, naturalism, philosophy, morality, and so on), thereby making it possible to overcome the criticism that medicalization has too often become meaningless (Hofmann, 2016).

The fourth step is to find out how different medicalizations relate to each other, given that the content of medical knowledge is blurred and adaptive (Cant and Sharma, 1999; Shuval et al., 2002), for example, users may absorb and use medical knowledge differently when they sit outside of biomedical jurisdiction and scientifically tested procedures (Baer and Coulter, 2008; Quah, 2008).

The fifth step is to ascertain if and how the different branches of knowledge exert social control in societies. Halfmann (2012) has mentioned that specific players, discourses, practices, and identities integrate medical social control in society through specific processes and at different levels. While social control can be exerted at macro level in the legislation, rulings, reports, and debates of national and international organizations, such as government bureaucracies, courts, legislatures, corporations, markets, universities, journals, foundations, non-profit organizations, and the media, at meso level it can be exerted by mission statements, reports, advertising, and procedures in local and regional organizations such as workplaces, hospitals, medical groups, clinics, nursing homes, schools, social service agencies, and prisons; and at micro level in face-to-face interactions (see Halfmann, 2012 for a detailed description). Consequently, my argument here is that different forms of medical knowledge can relate to specific ways of exerting social control over human conditions and behaviors.

\section{CONTRIBUTION TO THE CURRENT DEBATE ON MEDICALIZATION}

The standpoint of the knowledge-based approach to medicalization calls into question the empirical-based view of medicine and medical boundaries, thus affecting specifically the widely accepted definition of medicalization by Peter Conrad and concepts like biomedicalization and CAMization, rather than other concepts such as pharmaceuticalization (Abraham, 2010). Nevertheless, I do not claim to oppose Conrad's theories or biomedicalization and CAMization. My argument is that claims about the processes of medicalization, demedicalization, or remedicalization of human conditions and behaviors require the adoption of a clear understanding of what medicine is. This idea resonates with Conrad's own concern with the definition of medicalization, which was under discussion again in Williams et al.s (Williams et al., 2017) rejoinder to Busfield (2017). However, the way both contributions pose questions for future debate show the extent to which the overall understanding of medicalization remains, to a large extent, profession-based. The fact that biomedical knowledge started to govern daily life without the direct influence of its practitioners, thus contributing to the rise of medicine's social control, is the greatest expression of medicine's professionalization. For me a profession-based approach to medicalization results in the acceptance and reproduction of medical boundaries and definitions directly from biomedical knowledge. On the other hand, the standpoint of a knowledge-based approach adopts a view of medicine that considers its existence regardless of how it manifests empirically and acknowledges that medicine comprises different branches of knowledge whose boundaries are under constant adaptation.

If a knowledge-based view of medicalization is used, then both biomedicalization and CAMization actually articulate different forms of medicalization rather than alternatives to it. This is so because the knowledge and players often used to highlight alternatives to medicalization actually share medicine's ontological traits, thus proving the production of specific forms of medicalization (e.g., the concept of biomedicalization relates to medicalization by biological medicine and CAMization to medicalization by "complementary and alternative" medicines). A similar argument goes for those who argue that the medicalization of society is in decline. The role of midwives in homebirth is a good example used to support this position. In this case, I follow Busfield's (Busfield, 2017) arguments on the ongoing centrality of medicalization and say that opposition to medicalization is, at most, specific to biomedicine, whose effects may be harmless to other forms of medical knowledge. As Halfmann (2012) rightly argues, different branches of knowledge are able to exist and produce their own effects even when one specific branch of knowledge succeeds in monopolizing the institutionalization of medical social control over society.

\section{CONCLUDING REMARKS: AN OVERVIEW OF THE KEY ARGUMENTS}

The application of a knowledge-based approach to medicalization seeks to represent a way for the concept to overcome some of 
its criticism. Although several authors have sought to provide a comprehensive definition of medicalization, the fact that the medical/non-medical division is largely built on biomedical knowledge means that its conceptualization accepts and reproduces a view of medicine linked to the institutionalization of the medical profession. I have argued that such overlap of medicalization with biomedical knowledge fails to acknowledge that many different forms of medical knowledge can medicalize aspects of life. I named this widely accepted definition of medicalization as profession-based in order to highlight that it has to do with the process of closure that biomedicine went through, as this allowed it to exclude other branches of knowledge from the medical domain and to ensure its reproduction in society in the absence of the direct influence of its practitioners.

My view is that this understanding ignores three issues that are key to a theoretical scope of medicalization. One is that problems defined in medical terms, using medical language or treated through medical intervention are not unique to Western professionalized medicine that is built on biology and physiology. The second issue is that people's adherence to medical truths relies as much on the institutionalization of social control as on the perception of the effectiveness of treatments and cures. The third issue is that there are underlying features of clinicians' praxis that have remained relatively stable in the history of medicine. This argument draws on hermeneutical philosophy and seeks to legitimize the detachment of medicalization from biomedicine. I referred to two core features of medicine's ontology that apply to all medical branches: the scope of praxis and the aim of practice. As to the scope of praxis, medical decisions are intrinsically contingency-dependent. As to the aim of the practice, while the categories "health" and "disease" have changed drastically, the aim of medicine can be identified as the quest for ordered explanations and intervention aimed at treatment or healing.

Consequently, I argue that medicalization cannot be conflated with social control because medicine and social control stem from analytically independent dimensions that may or may not overlap in societies. One dimension is the fact that problems become defined in medical terms, i.e., conditions that are "medicalized." The other dimension is the process through which certain branches of medical knowledge institutionalize control over societies. While the former is specific to the medical realm, the second is specific to the government of societies. Detaching social control from medicalization protects Conrad's argument that medicalization comprises the dynamics of medicalization,

\section{REFERENCES}

Abraham, J. (2010). Pharmaceuticalization of society in context: theoretical, empirical and health dimensions. Sociology 44, 603-622. doi:10.1177/ 0038038510369368

Adler, P. A., and Adler, P. (2007). The demedicalization of self-injury: from psychopathology to sociological deviance. J. Contemp. Ethnogr. 36, 537-570. doi: $10.1177 / 0891241607301968$

Almeida, J. (2012). Towards the Camisation of health? The Countervailing Power of CAM in Relation to the Portuguese Mainstream Healthcare System. Doctoral thesis, Royal Holloway: University of London, Egham. demedicalization, and remedicalization of human conditions. These dynamics reflect disputes for social control exerted by different players and medical knowledge and not the issue of medicalization itself.

Conrad is right to stand up for medicalization as describing a problem in medical terms, using medical language to describe a problem, adopting a medical framework to understand a problem, or using medical intervention to treat it. What my knowledge-based approach highlights is that the definition of medical terms, the use of medical language and application of medical frameworks and intervention to treatment has to include all branches of medicine and is independent from the institutionalization of social control.

In short, the core aspect of the knowledge-based approach to medicalization is that it revisits the definition of medical knowledge and proposed one that is not normatively aligned to Western professional biomedicine. Consequently, it seeks to reconsider the ongoing debate of whether or not human conditions and behaviors face demedicalization in Western countries and to open the concept beyond the West, where medicalized behaviors and conditions exist apart from the institutionalization of biomedical control (e.g., Ayurveda in India).

\section{AUTHOR CONTRIBUTIONS}

The author confirms being the sole contributor of this work and approved it for publication.

\section{ACKNOWLEDGMENTS}

This article is a systematization of earlier ideas discussed with my students in the Medical Knowledge and Social Sciences graduate course. I am particularly indebted to them for their willingness to listen and question, as well as to Graça Carapinheiro, Carlos Ferreira, Manuel Silvério Marques, Mike Saks, and Tiago Moreira for their reading of and valuable comments on early versions of this manuscript. I also express my gratitude to the associate editor, NG, and the reviewers for the constructive review process.

\section{FUNDING}

The preparation of this article benefited from a research grant supported by FCT (SFRH/BPD/84175/2012).

Armstrong, D. (1983). Political Anatomy of the Body. New York: Cambridge. Atkinson, P. (1995). Medical Talk and medical Work. London: SAGE.

Baer, H., and Coulter, I. (2008). Introduction - taking stock of integrative medicine: broadening biomedicine or co-option of complementary and alternative medicine? Health Sociol. Rev. 17, 331-341. doi:10.5172/hesr.451.17.4.331

Ballard, K., and Elston, M. A. (2005). Medicalisation: a multi-dimensional concept. Soc. Theory Health 3, 228-241. doi:10.1057/palgrave.sth.8700053

Barker, K. K. (1998). A ship upon a stormy sea: the medicalization of pregnancy. Soc. Sci. Med. 47, 1067-1076. doi:10.1016/S0277-9536(98)00155-5

Bourdieu, P. (2004). Science of Science and Reflexivity. Chicago: The University of Chicago Press. 
Bradby, H. (2016). Research agenda in medical sociology. Front. Sociol. 1:14. doi:10.3389/fsoc.2016.00014

Broom, D., and Woodward, R. (1996). Medicalisation reconsidered: towards a collaborative approach to care. Sociol. Health Illn. 18, 357-378. doi:10.1111/14679566.ep10934730

Burke, M. C. (2011). "Resisting pathology: GID and the contested terrain of diagnosis in the transgender rights movement," in Sociology of Diagnosis (Advances in Medical Sociology), Vol. 12, eds P. J. McGann and D. J. Hutson (Bingley: Emerald Group Publishing Limited), 183-210.

Bury, M. (1986). Social constructionism and the development of medical sociology. Sociol. Health Illn. 8, 137-169. doi:10.1111/1467-9566.ep11340129

Busfield, J. (2017). The concept of medicalization reassessed. Sociol. Health Illn. 39, 759-774. doi:10.1111/1467-9566.12587

Cant, S., and Sharma, U. (1999). A New Medical Pluralism? London: UCL Press.

Clarke, A., Mamo, L., Fosket, J., Fishman, J., and Shim, J. (2010). Biomedicalization: Technoscience, Health, and Illness in the US. Durham: Duke University Press.

Conrad, P. (1975). The discovery of hyperkinesis: notes on the medicalization of deviant behavior. Soc. Probl. 23, 12-21. doi:10.2307/799624

Conrad, P. (1977). Medicalization, etiology and hyperactivity: a reply to Whalen and Henker. Soc. Probl. 24, 596-598. doi:10.2307/800129

Conrad, P. (1979). Types of medical social control. Sociol. Health Illn. 1, 1-11. doi:10.1111/j.1467-9566.1979.tb00175.x

Conrad, P. (1992). Medicalization and social control. Annu. Rev. Sociol. 18, 209-232. doi:10.1146/annurev.so.18.080192.001233

Conrad, P. (2005). The shifting engines of medicalization. J. Health Soc. Behav. 46, 3-14. doi:10.1177/002214650504600102

Conrad, P. (2007). The Medicalization of Society. Baltimore: The John Hopkins University Press.

Conrad, P., and Bergey, M. R. (2014). The impending globalization of ADHD: notes on the expansion and growth of a medicalized disorder. Soc. Sci. Med. 122, 31-43. doi:10.1016/j.socscimed.2014.10.019

Conrad, P., and Leiter, V. (2004). Medicalization, markets and consumers. J. Health Soc. Behav. 45, 158-176.

Conrad, P., and Schneider, J. (1980). Deviance and Medicalization: From Badness to Sickness. Philadelphia: Temple University.

Davis, J. (2006). How medicalization lost its way. Society 43, 51-56. doi:10.1007/ BF02698486

Downie, R., and Macnaughton, J. (2000). Clinical Judgment: Evidence in Practice. Oxford: Oxford University Press.

Ferngren, G. (2009). Medicine and Health Care in Early Christianity. Baltimore: Johns Hopkins University Press.

Foucault, M. (1979a). Discipline and Punish: The Birth of the Prison. New York: Vintage/Random House.

Foucault, M. (1979b). "La politique de santé au XVIIIe siècle," in Les Machines à Guérir. Aux origines de l'hôpital modern, eds M. Foucault, B. Kriegel, A. Thalamy, F. Beguin, and B. Fortier (Bruxelles: Mardaga), 13-27.

Fox, R. C. (1957). "Training for uncertainty," in The Student-Physician: Introductory Studies in the Sociology of Medical Education, eds R. K. Merton, G. Reader, and P. Kendall (Cambridge: Harvard University Press), 207-241.

Fox, R. C. (2000). "Medical uncertainty revisited," in The Handbook of Social Studies in Health and Medicine, eds G. L. Albrecht, R. Fitzpatrick, and S. C. Scrimshaw (London: SAGE), 409-427.

Freidson, E. (1970). Professional Dominance: The Social Structure of Medical Care. New Jersey: Transaction Publishers.

Furedi, F. (2008). "Medicalisation in a therapy culture," in A Sociology of Health, ed. D. Wainwright (London: SAGE), 97-114.

Gadamer, H. (1996). The Enigma of Health: The Art of Healing in a Scientific Age. California: Stanford University Press.

Halfmann, D. (2012). Recognizing medicalization and demedicalization: discourses, practices, and identities. Health 16, 186-207. doi:10.1177/1363459311403947

Hofmann, B. (2001). The technological invention of disease. Med. Humanit. 27, 10-19. doi:10.1136/mh.27.1.10

Hofmann, B. (2016). Medicalization and overdiagnosis: different but alike. Med. Health Care Philos. 19, 253. doi:10.1007/s11019-016-9693-6

Hughes, E. (1958). Men and Their Work. Glencoe: Free Press.

Johnson, D., and Chaudhry, H. (2012). Medical Licensure and Discipline in the United States: A History of the Federation of State Medical Boards. Baltimore: Johns Hopkins University Press.
Kelner, M., Wellman, B., Welsh, S., and Boon, H. (2006). How far can complementary and alternative medicine go? The case of chiropractic and homeopathy. Soc. Sci. Med. 63, 2617-2627. doi:10.1016/j.socscimed.2006.07.005

Kinsella, E. A., and Pitman, A. (2012). Phronesis As Professional Knowledge: Practical Wisdom in the Professions. Rotterdam: Sense Publishers.

Lahiri-Dutt, K. (2015). Medicalising menstruation: a feminist critiques of the political economy of menstrual hygiene in South Asia. Gend. Place Cult. 22, 1158-1176. doi:10.1080/0966369X.2014.939156

Lakatos, I. (1968). Criticism and the methodology of scientific research programmes. Proc. Aristotelian Soc. 69, 149-186. doi:10.1093/aristotelian/69.1.149

Larson, M. S. (2012). The Rise of Professionalism: Monopolies of Competence and Sheltered Markets. New Brunswick: Transaction Books.

Lindemann, M. (1999). Medicine and Society in Early Modern Europe - New Approaches to European History. Cambridge: Cambridge University Press.

Lowenberg, J., and Davis, F. (1994). Beyond medicalization-demedicalisation: the case of holistic health. Sociol. Health Illn. 16, 579-599. doi:10.1111/14679566.ep11348024

Lupton, D. (1995). The Imperative of Health: Public Health and the Regulated Body. London: SAGE.

McVaugh, M. (1993). Medicine before the Plague: Practitioners and Their Patients in the Crown of Aragon, 1285-1345. Cambridge: Cambridge University Press.

Montgomery, K. (2006). How Doctors Think: Clinical Judgment and the Practice of Medicine. Oxford: Oxford University Press.

Pinell, P. (2011). The genesis of the medical field: France, 1795-1870. Revue Française de Sociologie 52, 117-151. doi:10.3917/rfs.525.0117

Pitts, J. (1968). "Social control: the concept," in International Encyclopedia of Social Sciences, Vol. 14, ed. D. Sills (New York: McMillan), 381-396.

Porter, R. (1989). Health for Sale: Quackery in England, 1650-1850. Manchester: Manchester University Press.

Porter, R. (1995). Disease, Medicine and Society in England, 1550-1860. Cambridge: Cambridge University Press.

Porter, R. (1999). The Greatest Benefit to Mankind: A Medical History of Humanity. New York: W. W. Norton \& Company.

Quah, S. (2008). In pursuit of health: pragmatic acculturation in everyday life. Health Sociol. Rev. 17, 419-422. doi:10.5172/hesr.451.17.4.419

Riessman, C. (1983). Women and medicalization: a new perspective. Soc. Policy 14, 3-18.

Rose, N. (1994). "Medicine, history and the present," in Reassessing Foucault, eds C. Jones and R. Porter (London: Routledge), 48-72.

Rose, N. (2007). Beyond medicalization. Lancet 369, 700-703. doi:10.1016/ S0140-6736(07)60319-5

Saks, M. (1996). "From quackery to complementary medicine: the shifting boundaries between orthodox and unorthodox medical knowledge," in Complementary and Alternative Medicines: Knowledge in Practice, eds U. Sharma and S. Cant (London: Free Association Books), 27-43.

Saks, M. (2015). The Professions, State and the Market: Medicine in Britain, the United States and Russia. Abingdon: Routledge.

Shuval, J., Mizrachi, N., and Smetannikov, E. (2002). Entering the well-guarded fortress: alternative practitioners in hospital settings. Soc. Sci. Med. 55, 1745-1755. doi:10.1016/S0277-9536(01)00305-7

Szasz, T. (1970). Manufacture of Madness. New York: Dell.

Timmermans, S. (2010). "Evidence-based medicine," in Handbook of Medical Sociology, eds C. Bird, P. Conrad, A. Fremont, and S. Timmermans (Nashville: Vanderbilt), 309-323.

Torres, J. M. C. (2014). Medicalizing to demedicalize: lactation consultants and the (de)medicalization of breastfeeding. Soc. Sci. Med. 100, 159-166. doi:10.1016/j. socscimed.2013.11.013

Toulmin, S. (1993). "Knowledge and art in the practice of medicine: clinical judgment and historical reconstruction," in Science, Technology and the Art of Medicine, eds C. Delkeskamp-Hayes and M. Cutter (Dordrecht: Kluwer Academic Publishers), 231-249.

Wailoo, K. (2004). Sovereignty and science: revisiting the role of science in the construction and erosion of medical dominance. J. Health Polit. Policy Law 29, 643-659. doi:10.1215/03616878-29-4-5-643

Walker, J. (2013). How to Cure the Plague \& Other Curious Remedies. London: The British Library.

Weisz, G. (2003). The emergence of medical specialization in the nineteenth century. Bull. Hist. Med. 77, 536-575. doi:10.1353/bhm.2003.0150 
Wilensky, H. (1964). The professionalization of everyone? Am. J. Sociol. 70, 137-158. doi:10.1086/223790

Williams, S. (2002). Sleep and health: sociological reflections on the dormant society. Health 6, 173-200. doi:10.1177/136345930200600203

Williams, S. (2004). Beyond medicalization-healthicization? A rejoinder to Hislop and Arber.Sociol. Health Illn. 26,453-459. doi:10.1111/j.0141-9889.2004.00399.x

Williams, S., Coveney, C., and Gabe, J. (2017). The concept of medicalisation reassessed: a response to Joan Busfield. Sociol. Health Illn. 39, 775-780. doi:10.1111/ $1467-9566.12576$

Zola, I. (1972). Medicine as an institution of social control. Sociol. Rev. 20, 487-504. doi:10.1111/j.1467-954X.1972.tb00220.x
Conflict of Interest Statement: The author declares that the research was conducted in the absence of any commercial or financial relationships that could be construed as a potential conflict of interest.

Copyright (C) 2017 Correia. This is an open-access article distributed under the terms of the Creative Commons Attribution License (CC BY). The use, distribution or reproduction in other forums is permitted, provided the original author(s) or licensor are credited and that the original publication in this journal is cited, in accordance with accepted academic practice. No use, distribution or reproduction is permitted which does not comply with these terms. 